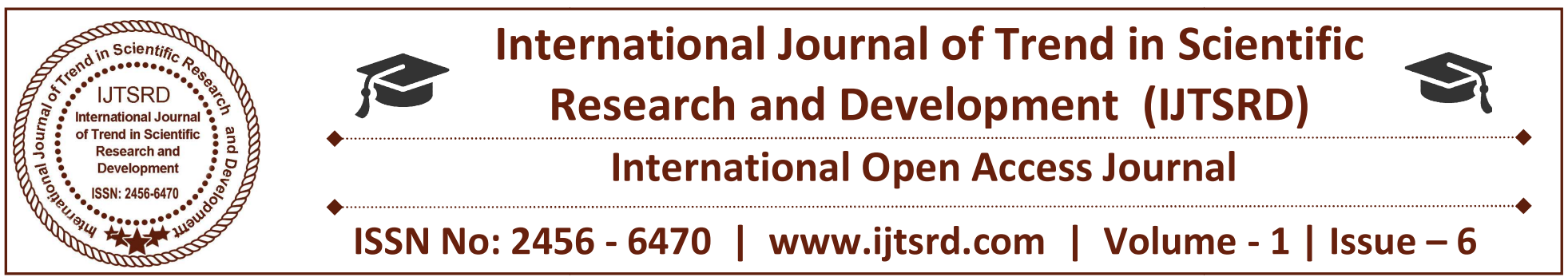

\title{
A Study on Legal Writing and Drafting
}

Vaishnavisri R

Student, BBA LLB (Hons), Saveetha School of Law, Saveetha University, Chennai

\author{
Ms. Bhanupriya \\ Assistant Professor, Saveetha School of Law, \\ Saveetha University, Chennai
}

\section{INTRODUCTION}

Legal writing is a form of technical writing generally used by professionals in the field of law. They are generally composed of complex, sequenced and interrelating sentences. Any legal writing must be formal, precise and in a well composed manner. Word choice and sentence construction is also an important key factor in legal writing such that everyone is able to understand. However the principle tool is language and vocabulary. A legal writer is the one who achieves this. Any person who has an ample amount of knowledge in law and moderate amount of writing skills could make a legal writer.

Attorneys pay plenty of their valuable time in drafting legal documents relevant to a case. A legal writer crafts associate degreed understands that truth price of an lawyer is in elbow grease judgment supported the information lined within the legal documents. He supports attorneys by making ready varied legal documents for them and therefore facilitate them get the most price of their time.

With access to advanced technology and superior quality, the standard of works is just associate degree art.

Although it's very difficult to keep their writing simple phrases and legal maxims cannot be omitted from their writing. It's very important to justify everything that is written. The job of a legal writer is to produce legal documents, information, drafts etc. in a written format to the legal industry.

\section{OBJECTIVES}

$>$ Legal writing is a vast field with numerous opportunities .

$>$ Legal writing is not the same as legal drafting .

\section{CHAPTER- 1 -LEGAL WRITING AND STEPS INVOLVED IN LEGAL WRITING}

In several legal settings specialised types of communication are needed. In several others, writing is that the medium during which a professional should categorical their analysis of a difficulty and look for to steer others on their clients' behalf. Any instrument should be curt, clear, and adapt to the target standards that have evolved within the profession.

There are typically 2 styles of legal writing. the primary sort needs a balanced analysis of a legal drawback or issue. Samples of the primary sort are inter-office memoranda and letters to purchasers. To be effective during this sort of writing, the professional should be sensitive to the wants, level of interest and background of the parties to whom it's addressed . A note to a partner within the same firm that details definitions of basic legal ideas would be inefficient Associate in Nursing an annoyance. In distinction, their absence from a letter to a consumer with no legal background may serve to confuse and complicate a straightforward scenario.

The second variety of legal writing is persuasive. Samples of this kind are appellant briefs and negotiation letters written on a purchasers behalf. The professional should persuade his or her audience while not agitating a hostile response through disrespect or by wasting the recipient's time with 
inessential data. In presenting documents to a court or body agency he or she should adapt to the specified document vogue.

Make sure you perceive the client's drawback. once given AN assignment, raise many queries. scan the relevant documents and take smart notes. Learn all you'll be able to regarding the client's state of affairs. If you are a junior asked to put in writing a note or a motion however you are not told something regarding the client's actual drawback, raise what it's in some detail. you want to be adequately briefed - and that is partially your responsibility. there is virtually no thanks to write a decent analysis note within the abstract. As you are reading cases and examining statutes, you will be in an exceedingly far better position to use your findings if you recognise the relevant specifics.

Strike the proper skilled tone: natural however not chatty. Some lawyers, particularly less practised ones being inspired to avoid expressive style, find yourself turning jubilantly informal and flouting the norms of normal English, particularly in email messages. for instance, they could write "u" rather than "you" and "cd" rather than "could." Some even use emoticons. though you discover yourself operating for a firm wherever some individuals do these items, exercise restraint. Use typical punctuation and capitalisation in your email messages. Your colleagues will not assume any less of you, and your supervisors can appreciate your expertness.

Master the approved entry word. ascertain what the standards are for citing authority in your jurisdiction. In CA, lawyers follow the $\mathrm{CA}$ vogue Manual. In ny, they must (but ofttimes don't) follow the ny Law Reports vogue Manual. In Texas, each knowledgeable professional follows the American state Rules of kind. alternative states have their own guides. And, of course, The Bluebook and also the ALWD Guide to Legal Citation are wide used as defaults (and typically needed by court rules). though you are not inclined to worry abundant regarding these items, you'd higher learn to obsess over them. Otherwise, you will look untutored.

Make your outline perceivable to outsiders. it is not enough to summarise. you need to summarise in an exceedingly manner that each conceivable reader - not simply the assignment lawyer-can perceive. therefore do not write your issue this way: "Whether Goliad will take a write-off on the unpaid area granted to Davidoff underneath I.R.C. $\S 170(f)(3)$ ?" that is incomprehensible to most readers as a result of it's too abstract and it assumes business executive information. Also, it does not show any mastery of the matter.

$>$ Don't be too tentative in your conclusions, however do not be too overconfident, either. school of law exams encourage students to use the one-hand-other-hand approach: the result can be this, or it can be that. Even knowledgeable lawyers generally hedge needlessly. This approach will look weak. what is needed is your best thought of however a court can return down on a problem.

Cut each unneeded sentence; then return through and cut each unneeded word. style makes your writing appear littered and under thought. Learn to delete each surplus word. for instance, general accord of opinion is doubly redundant: A accord relates solely to opinions, and a accord is general by its terribly nature. you'll be able to replace the phrase variety of with many or several. And so as to usually has 2 words too many - to will do the work alone. thus rather than so as to work out damages, write to work out damages.

\section{CHAPTER 2 - LEGAL DRAFTING AND IMPORTANT'S}

'Nomography' is that the name given to the topic that deals with the drafting of laws. It is, in different words, Legislative Drafting in a very broad sense. the target of 'Legislative Drafting' is to achieve beauty and utility, and, the draftsman's major responsibility is to achieve these 2 or strike a harmony between them.

Legislative Drafting is each a Science associated an Art. it's a science inasmuch as bound rules will be set down that area unit of universal application.

It is associate art because it consists of a way of the utilisation of language, along with a data of the technical interpretation. potency will be reached by obtaining mastery of the foundations, let alone talent or natural gift. 
Rather like associate creative person, World Health Organization decides on color, or sort of a musician placing at a specific tone, the draftsman ought to secure his 'sense' of fine drafting. His data of law speaks to his intelligence memory and judgment however, drafting could be a talent associated an art.

The draftsman is in point of fact a 'creative artist'. He provides kind or form to ideas, converts obscure ideas into concrete words, and reduces proposals: social, economic, political legal, reform etc. into writing.

He collects ideas from many sources and his method is artificial and not analytical.

Legislative drafting chiefly deals with the drafting of bills meant to become a section of civil law.

But in a very broader sense, it includes the drafting of statutory orders, rules and different directions issued by the Goyt.,

It conjointly includes the drafting of bye-laws of firms, municipalities and different sorts of subordinate legislation.

\section{Rules of Composition for Legislative Drafting.}

sure rules square measure to be followed if the draft ought to browse well and succeed the specified object.

The rules of composition follows in literary composition would be inadequate. Beauty in expression, is also achieved by following.

$>$ strictly literary rules meant to attain great thing about expression,

$>$ Rules peculiar to composition and

$>$ Rules of descriptive linguistics.

$>$ Here (i) \&amp; (iii) square measure to be invariably followed.

$>$ In addition the subsequent square measure the points touching the foundations peculiar to legal composition.

$>$ Legislation is generally meant to be a command for future obedience. generally it'd contain statement of reality handling the past that ought to be known as 'Preamble',

$>$ the straightforward phrase structure ought to be most well-liked to a compound or a posh sentence. If it's inevitable to use compound or sentence, care ought to be taken a minimum of to confirm that reader wouldn't drift. it's for this reason that it's invariably fascinating to range the varied clauses of prolonged sentences.

$>$ The operative portion of a neighbourhood ought to return 1st, and, exceptions, reservations or qualifications ought to be placed thenceforth.

$>$ the selection of words used shall be acceptable to the circumstances.

It is not the perform of the draftsman build | to form | to create $\}$ his draft learned he has got to make it straightforward of reading. Duplicating of words like 'null and void', "authorised and empowered' will be replaced by 'void' and 'authorised'.

A perfect sentence could be a sentence that doesn't scan wrong if the punctuation marks, are marked. The 'stop' shouldn't seem over once in an exceedingly sub-section; 'Provide that' ought to be preceded by a colon and not by a stop; coma shouldn't be used wherever one will do while not it; golf stroke a splash has been delineated as 'the most female of all the points' and intrinsically ought to be avoided.

The fashion or sensible legal composition ought to be free from all feeling and rhetoric. It should be impersonal, consistent and not contradictory and free from metaphors and figures of speech; embroidery not required. the feel ought to be firm, helpful and sturdy, 'A noble simplicity is its most stunning characteristic' (Bentham).

\section{CHAPTER 3 - DIFFERENCE BETWEEN LEGAL WRITING AND DRAFTING}

From a bird's-eye view, the primary objective of all legal writing is clear communication, so techniques that improve the quality of legal writing, generally, serve to improve the quality of drafted documents as well; however, although the terms are often erroneously used interchangeably, important distinctions exist between legal writing and legal drafting. "Legal writing" is the broader concept; it includes any intentional recording of words relating to law. "Legal drafting" is a narrower subset of legal writing; according to Black's Law Dictionary, "drafting" refers to the "practice, technique, or skill involved in preparing legal documents - such as statutes, rules, regulations, contracts, and wills - that 
set forth the rights, duties, liabilities, and entitlements of persons and legal entities." Although you might hear someone say, "I am drafting an appellate brief," this would be inaccurate because a brief does not set forth rights, duties, liabilities and entitlements. A brief falls under the penumbra of legal writing but not within the subset of legal drafting.

$>$ 1.Future-oriented vs. historical perspective. Legal drafting seeks to regulate the longer term actions of the parties; legal writing describes an occurrence that has already occurred and its known or cognizable ramifications. this implies that a author should be able to Associate in Nursingticipate future risks and to craft language which will make sure that the shopper isn't exposed to an unacceptable level of risk.

Long time period vs. short period. as a result of legal drafting seeks to regulate future actions, some contracts, wills, and statutes should be written to last well into the longer term. as an example, a series of attentiongrabbing cases involving a book publisher illustrated the confusing copyright problems that arose with the arrival of e-book technology 20 years once the contracts were signed. Similarly, a author charged with the responsibility of drafting a protracted term lease should craft language which will accommodate changes in banking technologies and payment systems. Conversely, briefs and pleadings are quickly forgotten, presumably even before the underlying case is resolved.

$>$ End-users vs. lawyers. though complaints and briefs are communications supposed for judges and alternative lawyers, most written documents are supposed to be utilised by nonlawyers. as an example, a executive can consult the written contract if and once he or she encounters a guaranty downside to search out out what remedies are obtainable and the way to pursue them.

Irregular reference vs. start-to-finish reading. though briefs and pleadings ar supposed to be browse from begin to end, the finish-user of a contract can consult specific provisions from time to time as problems arise throughout the term; he or she doesn't expect to possess to browse the complete contract from setting out to end to see, as an example, once payment is due. this implies that a contract ought to be organised in a very logical manner that enhances the end-user's ability to search out the required data. Of course, as lawyers, we have a tendency to avoid giving legal recommendation while not reading the complete contract as a result of we all know 1) contracts don't seem to be continuously organised well; and 2) one provision typically triggers another.

Some format vs. extremely such format. Everything a few temporary is specified: the allowable length; the margins; the scale of paper which will be used; the kind size which will be used; the fashion that has to be used; and then on. nearly nothing a few contract is such, which suggests the author is accountable for deciding what it ought to seem like, however long it ought to be, and what provisions ought to be enclosed to shield the client's interests and assign the suitable level of risk.

Minimal citation vs. integral citation. Citation of authority is associate integral element of briefs and pleadings, wherever statutes and case law precedents are quoted, cited, explained, and argued; citations in legal drafting are distributed and few. several contracts contain no citations in the slightest degree, however that doesn't mean that drafters don't ought to understand the law; drafters ought to take under consideration not solely the wants of applicable laws, that should be woven into written agreement provisions, however additionally the potential application of gap-filling laws just like the Uniform business Code and canons of construction that will creep into the interpretation and social control of the contract unless specifically excluded.

Cooperative vs. singular focus. A temporarywriter is charged exclusively with the responsibility of persuasively act his or her client's position; the opposing party's brief are going to be written by the opposing party's counsel. Conversely, in drafting for a negotiated dealings, the contract ultimately represents the interests of each parties; 
therefore, the parties should collaborate to provide one document that's acceptable to every of them. Drafting is cooperative in another sense: a contract is cooperative within the sense that provisions ar carried forward from one dealings to ensuing, that means that the origin and kinship group of any explicit provision are mostly unknown. though we tend to should assume that each one provisions should have served a crucial purpose at some purpose, the task for the writer is to work out whether or not every provision within the previous iteration has relevancy within the dealings at hand.

Crucial mistakes vs. correctible mistakes. Most briefs and pleadings will be amended by merely filing a motion with the court. In legal drafting, mistakes will be terribly expensive and therefore the solely methodology of correcting them once a contract has been signed is by persuading the opposing party to enter into a replacement contract — as a result of amendments to a contract are new contracts. for instance, a \$5,000,000 judgment during a Canadian case turned on the presumptively faulty placement of a comma.

$>$ Face up to scrutiny vs. persuade. In writing briefs and pleadings, the target is to steer the court to just accept your client's position. Opposing counsel might afflict your assessments of the proof or precedent; he or she might even object to your usage of a specific word or characterisation, however he or she wouldn't obtain to repudiate the that means of the temporary itself. Conversely, contracts should be ready to face up to attacks by extremely delicate lawyers zealously resolute disaffirming your supposed that means. As faculty member David Mellinkoff noted, drafters should always detain mind that "[s]ome day, somebody can browse what you have got written, attempting to search out one thing wrong with it. this is often the special burden of legal drafting, and therefore the special incentive to be as precise as you'll be able to."

\section{CONCLUSION}

With the demand for trained writers increasing, you'll be able to continually select this as your career possibility. If you have got a natural endowment for writing and a real interest in law, with very little follow you'll simply become a well known, a lot of sought-after legal author.

Job prospects area unit plentiful during this field. you'll be part of a house, magazine, or business firm, or do your own freelancing. This profession is predicted to grow at a awfully quick rate. in step with the U.S. Bureau of Labor Statistics, employment of writers and editors is predicted to grow by ten $\%$, or regarding as quick because the average for all occupations, from 2006 to 2016. Communication is that the verbalise the day and therefore the majority of corporations area unit exploitation this as a tool to push their company. Magazines, newsletters, websites, on-line publications, blogs, and plenty of alternative communication tools area unit getting used by corporations for his or her promotion. therefore writers and editors area unit positively planning to be in nice demand.

As you'll be able to see, drafters face several distinctive challenges attributable to their futureoriented endeavours. as a result of the objectives of legal drafting dissent considerably from the objectives of legal writing, most law students haven't been educated properly the way to draft in law school; they emerge from the sacred institutional walls with obvious deficiencies in transactional skills. 